\title{
JORGE L. BORGES: \\ EL SIGNIFICADO VERSUS LA REFERENCIA
}

\author{
POR \\ LELIA M. MADRID \\ University of Western Ontario
}

\begin{abstract}
El propósito de este artículo es explorar un problema central en la obra de Jorge Luis Borges: la interacción entre la similitud y la diferencia y, en este sentido, la relación adversa que guardan el significado y la referencia. ${ }^{1}$ A la vez, se intenta profundizar esta confrontación por medio del análisis de una (aparente) paradoja: la presencia de una infinitud textual conseguida por medio del privilegio de la similitud, esto es, la repetición de segmentos similares en distintos contextos, que se ve acompañada con una aguda conciencia de los límites. Podríamos esquematizar los términos del problema de la siguiente manera: la obra de Borges expone, por un lado, un movimiento de expansión (o reducción ${ }^{2}$ ) del significado conceptual y, por tanto, se aparta de aquello que los filósofos del lenguaje denominan definite reference. ${ }^{3}$ Por otro lado, está presente (y de manera muy explícita) la inscripción de la diferencia entendida como el límite temporal. Mi punto de partida para el análisis es el texto "Pierre Menard, autor del Quijote". 4

¿Qué escribe Pierre Menard? El reseñador-narrador nos informa que Menard es autor de una obra visible y asimismo de una obra invisible. Los libros, poemas, etc., que Pierre Menard ha traducido, comentado, parafraseado, etc., aunque son oscuros, existen realmente. Sin embargo, el status referencial de la obra visible de Menard está socavado por el hecho de que Menard no existe (existió). El atribuir un libro a un autor inexistente es una de las
\end{abstract}

\footnotetext{
'Este artículo es una versión corregida de una conferencia publicadada en Queen's University (marzo de 1993), en mi calidad de Distinguished Visiting Scholar para el año 1992-1993. Quisiera reiterar aquí mi sincero agradecimiento al Dr. John Walker del Departamento de Español e Italiano de la citada universidad por el honor de su invitación y, así mismo, a los colegas y autoridades de Queen's University por la hospitalidad con que me acogieron.

${ }^{2} \mathrm{He}$ reflexionado (desde otro ángulo) sobre este problema en otro lugar. Véase "Jorge L. Borges: la parodia del centro" en La fundacion mitológica de América Latina (Madrid: Fundamentos, 1989), 33-38.

${ }^{3}$ Respecto de la definite reference, véase por ejemplo, Keith Donnellan, "Proper Names and Identifying Descriptions", Synthèse 21 (1970), 335-358; también su "Reference and Definite Descriptions", en The Philosophical Review LXXV (July 1966), 281-304; Oswald Ducrot, Dire et ne pas dire (París: Hermann, 1980), 221-223; John Searle, Speech Acts: An Essay in the Philosophy of Language (Cambridge: Cambridge University Press, 1969), 81.

${ }^{4}$ Véase Jorge L. Borges, "Pierre Menard, autor del Quijote”, en Ficciones, Obras completas (Buenos Aires: Emecé, 1974).
} 
técnicas favoritas de Borges para subvertir la referencia. Por otro lado, el aspecto más interesante de la obra invisible de Menard es su reescritura del Quijote de Cervantes.

El texto de Borges nos ofrece dos pasajes que son idénticos, el de Cervantes y el de Menard, respectivamente:

... la verdad, cuya madre es la historia, émula del tiempo, depósito de las acciones, testigo de lo pasado, ejemplo y aviso de lo presente, advertencia de lo por venir.

... la verdad, cuya madre es la historia, émula del tiempo, depósito de las acciones, testigo de lo pasado, ejemplo y aviso de lo presente, advertencia de lo por venir (449).

Pero se nos advierte, sin embargo, que el Quijote de Menard “es (...) infinitamente más rico" (449). Obviamente, tal riqueza (tal transformación) del texto surge del nuevo contexto provisto por el lector/escritor. No obstante, ¿cómo puede un contexto generar un nuevo texto? Recordemos que el reseñador también expresa su admiración respecto del Quijote de Menard en los siguientes términos:

La historia, madre de la verdad; la idea es asombrosa. Menard, contemporáneo de William James, no define la historia como una indagación de la realidad sino como su origen. La verdad histórica, para él, no es lo que sucedió; es lo que juzgamos que sucedió. Las cláusulas finales - ejemplo y aviso de lo presente, advertencia de lo por venir- son descaradamente pragmáticas (449). ${ }^{5}$

Si aceptamos que el texto de Menard es "infinitamente más rico" (449), debemos admitir en él la presencia de nuevos elementos que no estaban en el Quijote de Cervantes. Pero, ¿cuáles son esos elementos, si admitimos que las palabras de Menard son literalmente las mismas que las de Cervantes? ¿Qué constituye este otro que aparece subrepticiamente en el texto? ¿Cómo puede lo Mismo ser eso y a la vez lo Otro? En otras palabras, ¿cómo puede cualquier texto expresar una diferencia respecto de sí y a la vez permanecer idéntico a sí mismo?

Al privilegiar la diferencia implícita en la lectura y en la interpretación, Borges trataba - deliberadamente - de subrayar un rasgo fundamental del lenguaje: el hecho de que el significado conceptual no posee fronteras definidas y puede ser moldeado ad infinitum. ${ }^{6}$

\footnotetext{
${ }^{5}$ No es una casualidad que Borges escogiera este pasaje del Quijote de Cervantes. De hecho, éste es el segmento en el que el significado de la "historia" es socavado por Cervantes (Don Quijote, Parte I, Capítulo 9). Sobre este problema, véase mi Cervantes y Borges: la inversión de los signos (Madrid: Pliegos, 1987), 41-44.

${ }^{6} \mathrm{He}$ reflexionado sobre el problema del significado conceptual versus la 'definite reference' en un volumen escrito en colaboración con Michael Issacharoff, De la pensée au langage (París: José Corti, en prensa). La tesis fundamental reposa sobre la redefinición del significado conceptual en tanto coexistencia de similitud ( $=$ los atributos comunes a una clase - concepto-) y diferencia (la manera como esos atributos están combinados, esto es, la diferencia funcional de los elementos pertenecientes a una clase). Debido a la dominancia de la similitud característica de todo concepto, se puede argüir que el significado carece de fronteras definidas. Este problema (y otros conexos) ha sido tratado en
} 
de sus segmentos. Las creaciones (órdenes) humanas son sólo sistemas, caracterizados por comienzos y fines inventados, artificiales. ${ }^{12}$ Y ello es lo que parece autorizar a Borges para inscribirlos (reescribirlos) en sus ficciones. Tal es el caso de la utopia tlöniana:

¿Cómo no someterse a Tlön, a la minuciosa y vasta evidencia de un planeta ordenado? Inútil responder que la realidad también está ordenada. Quizá lo esté, pero de acuerdo a leyes divinas - traduzco: a leyes inhumanas - que no acabamos nunca de percibir (442443).

Por ello también, no es un secreto que Borges haya privilegiado la parodia ya que en su juego de similitud/diferencia, aquélla reproduce irónicamente los límites presentes en toda empresa humana. Toda construcción que quiera explicar el mundo está limitada por su propia finitud que, a su vez, determina la imposibilidad de abarcarlo todo. Así, cada vez que al lector se le informa acerca de una comarca maravillosa, de una nueva taxonomía, de un espacio (humano) ordenado, la maravilla y el asombro serán traicionados (burlados) por la futilidad y la superfluidad de tales prodigios. Ni las sentencias magníficas de los filósofos, ni la elegancia de los perfectos hexágonos de la Biblioteca infinita, ni la inteligencia del detective Lönrot garantizan el conocimiento, o la supervivencia. Toda argumentación realizada por un filósofo, detective, etc., no conlleva nada más que belleza estética; sólo significa en tanto es literatura:

No hay ejercicio intelectual que no sea finalmente inútil. Una doctrina filosófica es al principio una descripción verosímil del universo; giran los años y es un mero capítulo cuando no un párrafo o un nombre - de la historia de la filosofía ("Pierre Menard ...", 449$450) \cdot{ }^{13}$

Se le recuerda entonces al lector que los sueños de infinitud y/o inmortalidad son peligrosos. Así en "El Inmortal" asistimos solamente "(al) bosquejo de una ética para inmortales". ${ }^{14} \mathrm{Si}$ nos fuera concedida la eternidad, ésta no nos permitiría trascender nuestra mera humanidad; a lo sumo quedaríamos confinados a la tediosa repetición de todas las acciones llevadas a cabo por todos los hombres. Porque ser inmortal es estar irrevocablemente condenado a repetir lo mismo:

Homero compuso la Odisea; postulado un plazo infinito, con infinitas circunstancias y cambios, lo imposible es no componer, siquiera una vez, la Odisea. Nadie es alguien, un solo hombre inmortal es todos los hombres. Como Cornelio Agrippa, soy dios, soy héroe, soy filosofo, soy demonio y soy mundo, lo cual es una fatigosa manera de decir que no soy.

(“El Inmortal”, 541).

12 Véanse sobre este problema (aunque desde otro ángulo) las reflexiones de Frank Kermode, The Sense of an Ending (New York: Oxford University Press, 1970), 89.

${ }^{13}$ Palabras que nos retrotraen al ensayo "El idioma analítico de John Wilkins", en Otras inquisiciones, 706-709, esp. 708: "La imposibilidad de penetrar el esquema divino del universo no puede, sin embargo, disuadirnos de planear esquemas humanos, aunque nos conste que éstos son provisorios". ${ }^{14}$ En El Aleph, Epílogo, 629 de la ed. cit de las Obras completas. 
La inmortalidad así concebida por Borges podría considerarse como uno de los extremos de esa "analogía perversa" de la que se ha hablado anteriormente. Porque ella implicaría la reducción de todas las identidades concebibles a lo idéntico, su mismidad total, sin la posibilidad de cambio ejercido por el tiempo. "(N)o (ser)" (en el caso del inmortal) llega a acercarse demasiado a la muerte, la fusión de todos ( $\mathrm{y}$ de todo) en un sólo hombre. ${ }^{15}$

Antes que mera repetición, la parodia es también el espacio de la diferencia. Si la repetición implica el subrayar la semejanza (de todos los esfuerzos humanos), la diferencia está provista (como se ha señalado más arriba) por el nuevo contexto. De hecho, es éste el que, haciendo tambalear la identidad del autor, socava la validez de las afirmaciones filosóficas y/o teológicas. Cuando el narrador-personaje de "La biblioteca de Babel" declara que:

La Biblioteca es una esfera cuyo centro cabal es cualquier hexágono, cuya circunferencia es inaccesible (466).

experimentamos una sensación de familiaridad que se une a la extrañeza. Recordamos a Pascal sumido en sus reflexiones sobre el hombre y el infinito, en búsqueda de un espacio adecuado para la naturaleza humana:

Car enfin, qu'est-ce que l'homme dans la nature? Un néant à l'égard de l'infini, un tout à l'égard du néant, un milieu entre rien et tout. Infiniment éloigné de comprendre les extrêmes, la fin de choses et leur principe sont pour lui invinciblement cachés dans un secret impénétrable, également incapable de voir le néant d'où il est tiré et l'infini où il est englouti. ${ }^{16}$

¿Qué queda de la sentencia de Pascal, "(Nature) (c')est une sphère infinie dont le centre est partout, la circonférence nulle part" $(179$, Ibid.)? ¿Qué subsiste de su estupor, su asombro ante el espectáculo del mundo? La famosa sentencia es reiterada en el contexto de una narración fantástica ("La biblioteca de Babel") y está emplazada en el seno de un entretejido de opiniones que afirman la infinitud de la biblioteca. Los límites de la identidad pascaliana se borran por obra de esta repetición. El texto se repliega, multiplica su significado y pierde así toda pretensión a la unicidad. La esfera de Pascal no es más la descripción hecha por el filósofo de la naturaleza (o el espacio), sino una oración escondida en un cuento fantástico que relata las vicisitudes de la biblioteca (el infinito). ${ }^{17}$ Como un libro o un capítulo que ya no conlleva autoridad en sí mismo, el pensamiento de Pascal sobrevive sólo como literatura. Su recontextualización lo ha privado de identidad: la referencia ha sido subvertida una vez más.

\footnotetext{
${ }^{15}$ Un caso similar es el Shakespeare de "Everything and Nothing" en El hacedor. Véase Obras completas, 803-804. La multiplicidad de lapersona (en su sentido etimológico) impide la actualización de la entidad única e identificable, esto es, la identidad.

${ }^{16}$ Blaise Pascal, Pensées, ed. André Wautier (París: Laffont, 1960), fragmento no. 388 [72 en la edición Brunschvicg], 178-186.

${ }^{17}$ Un efecto similar puede notarse en los ensayos sobre Pascal. Véase, por ejemplo, "La esfera de Pascal", en Otras inquisiciones, Obras completas, 636-638. En el caso citado, el empleo de un entretejido de opiniones desestabiliza el status referencial de las afirmaciones.
} 
Esta afirmación suena paradójica, sobre todo en el contexto de lo que se conoce como el significado dado por el diccionario, esto es, la definición de cualquier palabra en tanto proveniente del consenso de una comunidad de hablantes. Pero el significado puede también implicar una capa (o capas) semántica adicional que llega, a veces, a contradecir el significado convencional (regular) de una palabra. En tales casos, el contexto es, por supuesto, decisivo. ¿Cómo procede Borges para proveer de un nuevo contexto a sus textos?

Cada vez que Borges se apropia de oraciones, afirmaciones, provenientes de sus filósofos favoritos, o cada vez que atribuye sus afirmaciones a un filósofo, el resultado es la borradura de los límites semánticos normales de las palabras. Y por obra del mismo gesto, la noción de autoría queda socavada. De manera similar, cuando los lectores se enfrentan con la intrusión de la filosofía en los cuentos, o de un registro más claramente ficticio en sus ensayos, las fronteras entre los géneros se desmoronan porque las connotaciones significativas han cambiado. No es posible leer lo filosófico como tal; de manera análoga, lo ficticio adquiere reverberaciones filosóficas. El resultado de esta práctica es la expansión (semántica) del texto; por medio de las capas semánticas adicionales provistas por el nuevo contexto, cada palabra, afirmación, cada texto borgiano, revela facetas y potencialidades múltiples: son las versiones, siempre diferentes, de este nuevo Proteo. Y lo que es aún peor: cada nuevo "rostro" del texto es sólo otra (nueva) cara del significado: no hay nada sino lenguaje. Al desplegar el significado, al permitir el trabajo de la connotación por medio de nuevas combinaciones de signos, el lenguaje sólo media entre sus unidades lingüísticas, sólo expone el pasaje entre la semejanza y la diferencia implícitas en aquéllas. Ninguna trascendencia se ha añadido a los textos.

Si vacilamos cuando leemos el Quijote de Menard es simplemente porque esperamos encontrar a Cervantes $o$ a Menard: aguardamos ya sea la igualdad de lo mismo (que nos permitiría descartar la duplicidad: Cervantes es sólo Cervantes), o la diferencia (que nos permitiría identificar la obra u obras: Cervantes no puede ser Menard). En otras palabras, esperamos encontrarnos con una referencia definida. Es sumamente desconcertante tener que tratar con dos escritores al mismo tiempo. No es para nada cómodo tener que recordar constantemente que hemos de enfrentarnos con una fusión permanente de dos individuos, cuyas identidades permanecen difusas por obra de una constante redefinición de sus límites. Al inscribir el texto de Cervantes en el de Menard, Borges subraya además la idea de que ninguna interpretación (o lectura) de un texto es final. Ningún comentario puede agotar un texto simplemente porque

el terreno de los colores y los conceptos 'básicos' en los trabajos de Eleanor Rosch y de su equipo. Véanse, por ejemplo, Eleanor H. Rosch, "Natural Categories", Cognitive Psychology 4 (1973), 328 350; "On the Internal Structure of Perceptual and Semantic Categories", en Timothy E. Moore, ed., Cognitive Development and the Acquisition of Language (New York: Academic Press, 1973), 111 144; también Eleanor H. Rosch, Carolyn B. Mervis, Wayne D. Gray, David M. Johnson, and Penny Boyes-Braem, "Basic Objects in Natural Categories", Cognitive Psychology 8 (1976), 382-439. Es preciso señalar que Rosch no analiza el problema desde el ángulo estrictamente semánticolingúístico, sino psicológico. 
La literatura no es agotable, por la suficiente y simple razón de que un sólo libro no lo es. El libro no es un ente incomunicado: es una relacion, es un eje de innumerables relaciones ("Nota sobre (hacia) Bernard Shaw", 747). ${ }^{7}$

La diferencia que se origina de un nuevo contexto, surge en los textos de Borges, de un perverso uso de la analogía. Por medio de extrañas (a menudo asombrosas) asociaciones, Borges socava uno de los conceptos más caros a la civilización occidental: la identidad. ${ }^{8}$ Si algo (cualquier cosa) puede ser todo, si alguien puede ser todos los hombres, si lo familiar puede asemejarse a lo extraño (y viceversa), ¿qué distingue al uno del otro cuando los límites de esas entidades se han desdibujado?

No es sorprendente, por ello, que el lector se impaciente cuando se concluye en muchos de los textos con que cada hombre es (puede ser) todos los hombres. Decir, por ejemplo, que "Todos los hombres que repiten una línea de Shakespeare, son William Shakespeare" (438); \%, que " ¿Los fervorosos que se entregan a una línea de Shakespeare no son, literalmente, Shakespeare?", ${ }^{10}$ provoca desconcierto, incluso enojo. La identidad es nuestro último refugio, si lo demás estuviera por derrumbarse.

Para Borges, la identidad (de un texto literario, de los signos lingüísticos, del ser humano en tanto individuo) implicaría el establecer fronteras definidas y finales. Tal identidad impediría el diálogo entre la similitud y la diferencia dentro de la misma entidad, ${ }^{11}$ obstaculizaría la mezcla de géneros, de personajes, de significados. Y anunciaría en última instancia el apocalipsis de la infinitud (o el infinito) porque todas las posibilidades se hubieran constreñido por obra de los límites establecidos.

Sin embargo, ¿hasta qué punto se puede hablar de infinito en estos textos, si se subraya en ellos que el tiempo es el límite humano por excelencia? $\mathrm{O}$, dicho de otro modo: ¿cómo pueden los textos borgianos producir un efecto de infinitud si en tantos de ellos se parte de una aceptación de la temporalidad? La naturaleza multifacética de esos textos unida a la convicción de que el tiempo es la última frontera han constituido un enigma perpetuo para los lectores.

Los límites son parte fundamental de la literatura borgiana. Implican todo aquello que es humano y que impide que los hombres puedan alcanzar el conocimiento, esto es, la infinitud. Los límites humanos dan forma a los esfuerzos del hombre al tratar de comprender un universo que es infinito e irreductible. Así, toda creación humana expresa esos límites en cuyos márgenes ella ha llegado a originarse: los límites de nuestro razonamiento y, a su vez, los que conlleva todo sistema lingüístico. No existe ninguna creación (o construcción) humana que pueda contener la verdad (y la totalidad) acerca de la realidad o de cualquiera

\footnotetext{
7 Véase más adelante: “(S)i me fuera otorgado leer cualquier página actual —ésta, por ejemplocomo la leerán el año dos mil, yo sabría como será la literatura del año dos mil" (747).

${ }^{8}$ No es extraño, por ello, que se carezca en estos textos de "referencias definidas". Las entidades singulares, únicas, identificables (= con límites definidos) que constituyen instancias de "definite reference", son las que están ausentes en muchos de los textos de Borges.

${ }^{9}$ En "Tlon, Uqbar, Orbis Tertius", Ficciones, ed. cit. de las Obras completas.

${ }^{10}$ En Otras inquisiciones, Obras completas, 763.

"El caso del Quijote de Cervantes-Menard sería un ejemplo muy claro en este sentido.
} 
Pero la repetición socava la autoridad del discurso filosófico de otra manera. Inscribe la filosofia dentro del universo de la literatura porque destaca la reiteración de lo Mismo: en los términos borgianos, "metáforas"(véase más adelante). Esta es otra de las consecuencias extremas de la repetición que se ejerce como perversa analogía. La sentencia de Pascal, por ejemplo, aparece asimismo en el ensayo, "La esfera de Pascal", que explora los antecedentes de tal pensamiento en la filosofia y la literatura griega, italiana y francesa (636-638):

Seis siglos antes de la era cristiana, el rapsoda Jenófanes of Colofón, (...) propuso a los griegos un solo dios, que era una esfera eterna. (...). Parménides, cuarenta años después, repitió la imagen ("el Ser es semejante a la masa de una esfera bien redondeada, cuya fuerza es constante desde el centro en cualquier dirección") (...).

La historia universal continúo su curso, los dioses demasiado humanos que Jenófanes atacó fueron rebajados a ficciones poéticas o a demonios, pero se dijo que uno, Hermes Trismegisto, había dictado un número variable de libros (...), en cuyas páginas estaban escritas todas las cosas. Fragmentos de esa biblioteca ilusoria, compilados o fraguados desde el siglo III, forman lo que se llama el Corpus Hermeticum; en alguno de ellos, o en el Asclepio, que también se atribuyó a Trismegisto, el teólogo francés Alain de Lille Alanus de Insulis- descubrió a fines del siglo XII esta fórmula, que las edades venideras no olvidarían: "Dios es una esfera inteligible, cuyo centro está en todas partes y la circunferencia en ninguna". (...) En el siglo XIII, la imagen reapareció en el simbólico Roman de la Rose, que la da como de Platón, y en la enciclopedia Speculum Triplex; en el XVI, el último capítulo del último libro de Pantagruel se refirió a "esa esfera intelectual, cuyo centro está en todas partes y la circunferencia en ninguna, que llamamos Dios" (...) (636-637).

El ensayo nos provee de numerosas fuentes de modo de demostrar que "(q)uizá la historia universal es la historia de la diversa entonación de algunas metáforas" (638). Una y otra vez, el lector se ve confrontado con la recurrencia de lo mismo a través de diversas épocas y culturas. ¿Coincidencia? ¿Influencia? Nunca podremos saberlo de manera cierta.

De acuerdo con Borges las ideas son pocas y son las mismas. Sólo la manera de formularlas (= el contexto) cambia. Postulado un infinito período de tiempo, toda metáfora humana acabará por ser recreada incontables veces. Por ello, imaginar un escritor simbolista que trata de escribir Don Quijote de nuevo es simplemente llevar esta certidumbre a sus últimas consecuencias.

"La esfera de Pascal" (como muchos otros ensayos) no sólo ofrece un catálogo de pensamientos increíblemente similares al de Pascal, sino que destaca la pobreza de la imaginación humana: el hombre se distingue del resto de la Creación porque sólo puede repetir. Si la Creación (el Universo) es también el dominio de la repetición, corporeiza sin embargo un orden desconocido para el hombre, las leyes naturales que no se originaron en (con) él. ${ }^{18}$

El razonamiento y la imaginación humanas sólo pueden recrear, transponer, traducir un puñado de metáforas. Si la repetición lo permea todo, los seres humanos se parecen los

${ }^{18}$ Los límites dados pueden redefinirse como no humanos en tanto no tienen su origen en la intervención de los hombres. 
unos a los otros: "somos (...) los otros"19 y nada es nuevo bajo el sol. ${ }^{20}$ La repetición y la consecuente falta de originalidad son el sello de lo humano. Toda teoría, sistema o postulado ocurre en el dominio de la repetición porque no puede eludirla. Ella es nuestro lugar de residencia.

Pero la repetición es el único infinito accesible al hombre. Y me refiero aquí a la sola infinitud posible para Borges: el universo del lenguaje, de la literatura y el mito -la herencia de los siglos.

En tanto "infinito", el mito puede ser una consolación. No es sorprendente que los historiadores de las religiones y los antropólogos hayan hablado del tiempo instaurado por el mito como el Gran Tiempo, una suerte de eterno presente. ${ }^{21}$ Así entendido, el tiempo mítico encarnaría un intento de trascender el límite de la temporalidad. Pero la infinitud que el mito configura es sólo un pálido reflejo, una semblanza simbólica de lo inalcanzable: la eternidad.

El orden simbólico parece acoger la única infinitud posible para el hombre. La falta de límites semánticos definidos (de fines y de comienzos), lo hace virtualmente infinito. Es imposible aprehender la totalidad del lenguaje, o la mayoría de sus combinaciones o posibles permutaciones. Aquellos ensayos borgianos que se centran en las diversas versiones de una idea (o metáfora, como diría Borges) subrayan este hecho. El objetivo de tales textos no reside entonces en las ideas (específicas) que puedan expresar sino en la virtual infinitud de su significado, en esa interacción entre la similitud y la diferencia implícita en la estructura de los conceptos.

En este contexto, una obra entera se hace comparable a una ideay viceversa. La entidad mayor equivale a una oración y ésta a aquélla. Es preciso recordar lo que expresara Borges en "El Zahir":

Dijo Tennyson que si pudiéramos comprender una sola flor sabríamos quiénes somos y qué es el mundo. Tal vez quiso decir que no hay hecho, por humilde que sea, que no implique la historia universal y su infinita concatenación de efectos y causas (594).

Si todo el universo puede encontrarse en cualquier segmento de la realidad, la falta de fronteras característica de todo concepto permite interminables asociaciones entre las categorías. ${ }^{22}$ Lo pequeño puede expandirse porque las asociaciones que pueden realizarse

\footnotetext{
${ }^{19}$ En el texto de la solapa de las Obras completas en colaboración (Buenos Aires: Emecé, 1979). El párrafo reza así: "Quizá no huelgue recordar que los libros más personales - la Anatomía de la Melancolía de Burton y los ensayos de Montaigne-son, de hecho, centones. Somos todo el pasado, somos nuestra sangre, somos la gente que hemos visto morir, somos los libros que nos han mejorado, somos gratamente los otros" (el subrayado es mío).

${ }^{20}$ Véase el poema, "Eclesiastés, I, 9", en La cifra (Buenos Aires: Emecé, 1981), 27-28.

${ }^{21}$ Véase especialmente Mircea Eliade, The Myth of the Eternal Return, trans. Willard R. Trask (London: Routledge \& Kegan Paul, 1955).

${ }_{22}$ Véase, desde otra perspectiva, Maurice Blanchot, Le livre à venir (París: Gallimard, 1959), 142: “Ainsi, le monde, s'il pouvait être exactement traduit et redoublé en un livre, perdrait tout commencement et toute fin et devien drait ce volume sphérique, fini et sans limites, que tous les hommes écrivent et où ils sont écrité ce ne serait plus le monde, ce sera le monde perverti dans la somme infinie de ses possibles" (el subrayado es mío).
} 
son ilimitadas. De manera similar, es posible reducir una entidad al privarla de un posible número de asociaciones. La similitud se expande con la adición de la diferencia; la diferencia (laidentidad) se transforma en abstracción (concepto) por obra de generalizaciones. Y, por supuesto, estas versiones e inversiones son la materia de que están hechos los mitos. No es una sorpresa, entonces, que Borges acordara un rol fundamental a la lectura y a la memoria.

En un memorable ensayo ("Fantasia of the Library"), Michel Foucault declaraba que en la obra de Flaubert (como en la de Borges) la biblioteca estaba en llamas. ${ }^{23} \mathrm{Si}$ tomáramos esta afirmación literalmente, podría añadirse que aquí los libros se queman para que se diluyan los significados (normales), para que la lectura (y la memoria de esa lectura) puedan mezclar las páginas interminablemente. Alejandría está en llamas. La supervivencia - la memoria- del libro será mítica. Las consecuencias no son menos importantes.

Lo mítico implica la subversión de toda referencia (definida) en los textos. Cuando Borges emplaza ideas o episodios similares en diferentes latitudes y épocas, el hecho queda desprendido de sus coordenadas espacio-temporales. Los nombres de lugares y las referencias a un tiempo específico (cuando ocurren) se hacen irrelevantes, porque tales lugares no existen (caso de Tlön, de Triste-le-Roy, etc.), o porque los datos temporales se anulan en el entretejido de citas (u opiniones) llevado a cabo por la voz narrativa. Borges llega incluso a declarar en el prólogo a Artificios lo siguiente:

Ya redactada esa ficción ["La muerte y la brújula"], he pensado en la conveniencia de amplificar el tiempo y el espacio que abarca: la venganza podría ser heredada; los plazos podrían computarse por años, tal vez por siglos; la primera letra del Nombre podría articularse en Islandia; la segunda, en Méjico; la tercera, en el Indostán (483).

En términos generales, podría decirse que en la literatura borgiana la materia prima de un argumento reside en aquellos eventos susceptibles de transformarse en hechos de carácter universal. Para conseguir este efecto, lo que sucede es generalizado o, a veces, reducido a su esqueleto de modo que devenga arquetípico. ${ }^{24}$ Una narración no puede constituirse como tal si no concierne a todos - y a nadie-; así, el individuo no tiene cabida en este esquema. Un cuento no debe ser "válido" para un lugar (o un tiempo) específico sino para todo el mundo. Es el caso de "El hacedor"25 en el que un par de humildes episodios de la vida de Homero se trasponen en dos hechos arquetípicos de amor y de odio. Los detalles particulares del caso poco importan; de cualquier modo, la memoria no puede recuperar los hechos de la manera como sucedieron. El recuerdo (que es otra variante de

\footnotetext{
${ }^{23}$ Véase Michel Foucault, Language, Counter-Memory, Practice, ed. Donald F. Bouchard (Ithaca: Cornell University Press, 1977), "Fantasia of the Library", 92.

${ }^{24}$ Incluso ciertas afirmaciones pueden adquirir cualidad arquetípica por obra de su constante repetición en distintos contextos.

${ }^{25}$ Véase mi “"Fundación mítica de Buenos Aires' o la utopía de la historia", en Bulletin of Hispanic Studies, LXIX, 4 (October 1992), 347-356.
} 
la repetición en la literatura borgiana) se traduce por medio de arquetipos, historias que se repiten y cuyos comienzos y fines se han desdibujado: la Iliada y la Odisea. ${ }^{26}$

Así, la repetición se aúna a la mezcla de diferentes registros y autores, al olvido y veleidades de la memoria: lo particular se desvanece y los textos se transforman en narraciones de carácter mítico. La expansión de la similitud a través de asociaciones y la generalización de la identidad en el tipo (o arquetipo) asegura un permanente reciclaje de lo mismo en lo otro y viceversa. El lector circula así en un espacio difuso, cuyas fronteras retroceden y avanzan constantemente: una "mala infinitud" ${ }^{27}$ desprovista de psicología, autoría, referencia.

Por supuesto, las consecuencias en el ámbito de los personajes no son menos importantes. Si parece simplista expresar que los personajes borgianos carecen de psicología porque no tienen identidad definida, no lo es en lo que concierne a las consecuencias textuales. ${ }^{28}$ Sabemos que estos personajes son reversibles, capaces de convertirse en sus opuestos. ${ }^{29}$ Su voz no es confiable; no estamos seguros respecto de si lo que se dice proviene de ellos o si alguien (¿quién?) se lo atribuye. El personaje borgiano es, por lo general, anónimo. No es la entidad única, identificable y definible por la diferencia. ${ }^{30}$ Por el contrario, todo y todos se parecen sospechosamente: Browning y Homero pueden ser Borges, Shakespeare es todos, Whitman es el mundo y los que pueblan su poesía. ${ }^{31}$ Tratar de descifrar las ilimitadas posibilidades implícitas en estas ecuaciones es vertiginoso. Más aún, es imposible intentar pensar en límites, esto es, en identidades.

No es por ello una sorpresa que se privilegie al lector a expensas del autor. Porque la lectura es una operación anónima, que no está confinada a nadie en particular: es el espacio de la interminable metamorfosis de los textos. Memoria y signos que se desvanecen y desdibujan son parte fundamental del proceso de la lectura. En tal actividad, no es posible plantearnos el problema de un sistema de diferencias/identidades:

(U)n libro es más que una estructura verbal, o que una serie de estructuras verbales; es el diálogo que entabla con su lector y la entonación que impone a su voz y las cambiantes y durables imágenes que deja en su memoria. Ese diálogo es infinito; las palabras amica silentia lunae significan ahora la luna intima, silenciosa y luciente, y en la Eneida significaron el interlunio, la oscuridad que permitió a los griegos entrar en la ciudadela de Troya ... ("Nota sobre (hacia) Bernard Shaw", 747).

26 "Historias" es el título irónico dado por Borges a algunas de sus colecciones (Historia Universal de la Infamia, Historia de la eternidad). Pero si acordamos en que no hay historia sin fechas o lugares específicos (identificables), ¿donde podemos ubicar estos textos borgianos?

${ }^{27}$ En la terminología de Blanchot; véase Le livre à venir, 140.

${ }^{28}$ Véase Silvia Molloy, Las letras de Borges (Buenos Aires: Sudamericana, 1979), 51-59.

${ }^{29}$ Véase Jaime Alazraki, Jorge Luis Borges (New York: Columbia University Press, 1971).

${ }^{30}$ Respecto del status del personaje en relación con la "definite reference", see Michael Issacharoff, Lieux comiques ou le temple de Janus (París: José Corti, 1990), esp. páginas 35-45; "Bobby Watson and the Philosophy of Language", French Studies, XLVI, 3 (July 1992), 272-279.

${ }^{31}$ Véase, por ejemplo, "Browning resuelve ser poeta", en La rosa profunda, Obra poética, 1923-1977 (Madrid: Alianza, 1987), 424-425; "Nota sobre Walt Whitman", en Discusión, Obras completas, 249-253. 
El diálogo, ese fenómeno humano reversible que siempre desplaza sus términos para realizarse, define asimismo la escritura de Borges. Y como en todo diálogo, los textos de Borges cambian sin cesar. Memoria, lectura, diálogo, son algunas de las versiones borgianas de la infinitud.

Por todas las razones antes enunciadas, sería difícil - si no inverosímil- hablar de una teoría en el caso de la literatura borgiana. Si tal cosa fuera posible, sus textos habrian cristalizado como en esos espejos "abominables" que Borges aborrecía. ${ }^{32}$ La similitud y la diferencia se habrían fusionado para constituir una sola entidad: la identidad. El significado se hubiera reducido a una definición única y estable, probablemente a la pura referencia. En otras palabras, tendríamos un sistema de diferencias. Pero es imposible acceder a una teoría, esto es, un orden, en esta heterotopía, ${ }^{33}$ este espacio desprovisto de principios y de fines. ${ }^{34}$

El siguiente pasaje puede ayudarnos a entender la naturaleza del arte de acuerdo con Borges:

La música, los estados de felicidad, la mitología, las caras trabajadas por el tiempo, ciertos crepúsculos y ciertos lugares, quieren decirnos algo, o algo dijeron que no hubiéramos debido perder, o están por decir algo; esta inminencia de una revelación, que no se produce, es, quizá, el hecho estético ("La muralla y los libros", 635). ${ }^{35}$

El arte no es entonces el espacio de la utopía, la tierra de ensoñación de contornos definidos y de lugares ya asignados para cada uno. El arte (y la literatura) son infinitos porque se originan en la imprecisión y la no realización. Quizá una mejor apreciación de tal problema puede encontrarse en el poema "Arte poética":

Cuentan que Ulises, harto de prodigios,

Lloró de amor al divisar su Itaca

Verde y humilde. El arte es esa Itaca

De verde eternidad, no de prodigios.

También es como el río interminable

Que pasa y queda y es cristal de un mismo

Heráclito inconstante, que es el mismo

Y es otro, como el río interminable. ${ }^{36}$

\footnotetext{
${ }^{32}$ Véase "Tlön, Uqbar, Orbis Tertius", 431 y 432.

${ }^{33}$ Término acunado por Michel Foucault en su brillante prefacio a Les mots et les choses. Une archéologie des sciences humaines (París: Gallimard, 1966), 9.

34 Véase Maurice Blanchot, Le livre à venir, ed. cit., 140: “Avant d'avoir commencé, déjà on recommence; avant d'avoir accompli, on ressasse, et cette sorte d'absurdité consistant à revenir sans être jamais parti, ou à commencer par recommencer, est le secret de la 'mauvaise' éternité, correspondant a la 'mauvaise' infinité, qui l'un et l'autre recèlent peut-être le sens du devenir". Véanse también mis comentarios en mi trabajo Cervantes y Borges: la inversión de los signos, especialmente páginas 111-135.

${ }^{35}$ En Otras inquisiciones, Obras completas, 633-635.

${ }^{36}$ En El hacedor, Obras completas, 843.
} 
Si es humilde y pobre, el arte no es el lugar de la definición; si es eterno, es porque siempre reescribe el pasaje del tiempo, su constante repetición y cambio:

(N)o puedo caminar por los arrabales en la soledad de la noche, sin pensar que ésta nos agrada porque suprime los ociosos detalles, como el recuerdo; no puedo lamentar la perdición de un amor o de una amistad sin meditar que sólo se pierde lo que realmente no se ha tenido; (...) cada vez que recuerdo el fragmento 91 Heráclito: "No bajarás dos veces al mismo río", admiro su destreza dialéctica, pues la facilidad con que aceptamos el primer sentido ("El río es otro") nos impone clandestinamente el segundo ("Soy otro") y nos concede la ilusión de haberlo inventado; (...). Esas tautologías (y otras que callo) son mi vida entera ("Nueva refutación del tiempo", 763). ${ }^{37}$

Esta nueva refutación (repetición) del tiempo (el límite) no puede obliterarlo. Porque la repetición es, para Borges y en última instancia, nada más que tautología. Tautologías, no creaciones (no Diferencias), son la materia de la que está hecha la vida. Si los seres humanos, si los literatos (como Borges-Menard) están destinados a repetir lo mismo, sus abstracciones, esto es, sus palabras y sus mitos, los sobrevivirán. Alejandría puede quemarse con sus libros, pero no la tautología, no aquello que volverá a repetirse y a reescribirlos/leerlos:

Cuando se acerca el fin, ya no quedan imágenes del recuerdo; sólo quedan palabras. No es extraño que el tiempo haya confundido las que alguna vez me representaron con las que fueron símbolos de la suerte de quien me acompañó tantos siglos. Yo he sido Homero; en breve, seré Nadie, como Ulises; en breve, seré todos: estaré muerto ("El inmortal", 543 544).

${ }^{37}$ En Otras inquisiciones, Obras completas. 